\title{
Variation of bleeding time and clotting time in the ABO blood groups
}

\author{
Seerina Adhikari Manandhar, Mrigendra Amatya
}

\section{Author(s) info:}

Department of Physiology,

Nepal Medical College and

Teaching Hospital, Attarkhel,

Gokarneshwor-8, Kathmandu, Nepal

\section{Correspondence:}

Dr. Seerina Adhikari Manandhar BDS, MD

Department of Physiology, Nepal Medical College and Teaching Hospital, Attarkhel, Gokarneshwor-8, Kathmandu, Nepal

Email:

seerina1978@gmail.com

DOI :

https://doi.org/10.3126/jpsn.v1i2.42287

\begin{abstract}
Introduction: Blood grouping, bleeding time (BT) and clotting time (CT) are important hematological parameters investigated before any surgical procedure. The association of blood groups with many diseases are established, such as epistaxis with blood group "O". This study aimed to assess the relationship of BT and CT among different blood groups and to find any gender difference in these parameters.
\end{abstract}

Materials and methods: A cross-sectional observational study was conducted among healthy medical students. Blood grouping was done by agglutination method, BT by Duke's method, and CT by capillary tube method. Mean bleeding and clotting times (seconds) were compared among groups.

Results: The study was completed in 351 students (160 males, 191 females), with age ranging from 19-23 years. Both BT and CT values were highest in the blood type O, BT was lowest in type B, and CT was lowest in type $A B$, although the differences were statistically not significant $(\mathrm{p}>0.15)$. Females had higher values of $\mathrm{BT}$ as well as CT than males ( $p$ values $<0.001$ ). A very highly significant correlation between the bleeding and clotting times was also noticed (Pearson's correlation coefficient, $\mathrm{P}=0.495, \mathrm{p}<0.001$ ).

Conclusions: The study hinted a tendency for higher risk for hemorrhagic condition and lower risk for thrombotic event in blood group $\mathrm{O}$ compared to groups $\mathrm{A}, \mathrm{B}$ or $\mathrm{AB}$. Multicentric study including larger population with the emphasis on finding plasma vWF level may be helpful to verify findings, identify the risk groups, and take prior preventive measures.

Keywords: $\mathrm{ABO}$ blood group, bleeding time (BT), clotting time (CT), von Willebrand factor (vWF)
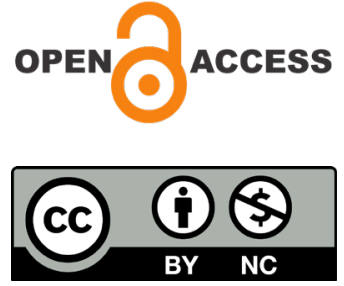

(C) JPSN 


\section{INTRODUCTION}

In the $\mathrm{ABO}$ blood grouping system, an individual is classified as $\mathrm{A}, \mathrm{B}, \mathrm{AB}$, or $\mathrm{O}$ according to the presence and absence of antigens $\mathrm{A}, \mathrm{B}$, both $\mathrm{A}$ and $\mathrm{B}$, or neither on the red blood cell surface. Consequently, the individual's plasma would contain antibodies against $\mathrm{B}, \mathrm{A}$, neither, or both $\mathrm{A}$ and $\mathrm{B}$ respectively. This serological difference between the individuals was first described by Landsteiner in 1900. This discovery of blood group systems laid a scientific basis for safe practice of blood transfusion, organ transplantation, surgical procedures and is also useful in determining some other immunological characteristics. They have also been used as genetic markers in studies of their association with various diseases.[1,2]

Blood groups has been correlated with many diseases. The most established associations are the correlation of gastric carcinoma with blood group A and duodenal ulcer with blood group O. Other associations are thromboembolic disorders with blood group A, urinary tract infection in females with blood group B.[1]

Some studies have also found that individuals with blood group $\mathrm{O}$ have higher incidence of epistaxis in comparison to those with other $\mathrm{ABO}$ blood groups.[3] It has been observed that people with blood group $\mathrm{O}$ expressed low von Willebrand factor (vWF).[4] It is a blood glycoprotein involved in hemostasis, synthesized by endothelial cells and megakaryocytes. [5] It helps in platelet adhesion and platelet aggregation. It also acts as a special carrier protein for the clotting factor VIII (antihemophilic factor A).[6] This may highlight upon the influences of $\mathrm{ABO}$ blood groups on the bleeding time and clotting time of an individual.

Bleeding time (BT) is the time from the onset of bleeding to the formation of temporary hemostatic plug that stops the bleeding. The temporary hemostatic plug is being formed by the aggregation of platelets when the platelets come in contact with exposed collagen and adhere with collagen and to the protein called vonWillebrand factor. It is mainly a test to assess the platelet adhesion and aggregation and can be prolonged significantly in thrombocytopenia and conditions with defective platelet functions, either congenital or acquired.[7] The time interval from the onset of bleeding to fibrin threads formation or clot formation is the clotting time. Clotting time (CT) is prolonged in conditions in which clotting factors are defective or deficient. The normal values of bleeding time generally lie in the range of 1-5 $\mathrm{min}$. The normal clotting time ranges between 2-8 $\mathrm{min}$.[7] Nowadays, these tests are widely used not just for evaluation of platelet function but also to assess the effects of medications and medical devices (Such as cardiopulmonary bypass or dialysis machines) on homeostasis status. [8]. However, in the modern world, newer platelet function instruments are available that can monitor the efficacy of anti-platelet therapy as well as platelet hyper-function slowly being incorporated into routine clinical use and can be utilized as not only as general screening tests of platelet function but to monitor anti-platelet therapy and to potentially assess both risk of bleeding and/or thrombosis. [9]

Studies have been conducted to explore the relationship between different blood groups with these parameters of hemostatic function. Both BT and CT have been usually found to be prolonged in blood group $\mathrm{B}$ or $\mathrm{O}$, but not in all studies. [4, 1216] We aimed to verify the relationship of bleeding time and clotting time among different blood groups and also to find out if there is any gender differences between these parameters among the healthy young subjects.

\section{MATERIALS AND METHODS}

A cross sectional observational study was conducted on 351 students of 1st year MBBS and BDS from the year 2017 to to 2020 over a period of 4 years. The age of the subjects ranged from 19-23 years. The study was conducted in the Hematology Laboratory in the Department of Physiology, Nepal Medical College and Teaching Hospital, Attarkehel, Jorpati, Kathmandu, Nepal. The students who had the history of hematological disorders, had recently taken medication of the NSAID group, or antiplatelet and anticoagulant drugs were excluded. Although the total of 376 subjects were initially involved, 25 subjects were excluded due to the unavailability of complete data.

After obtaining informed consent, $\mathrm{ABO}$ and $\mathrm{Rh}$ blood groups were determined by agglutination method. The blood samples were mixed with antisera $\mathrm{A}, \mathrm{B}$ and $\mathrm{D}$, respectively and the clumping of RBCs was verified under the microscope to identify the blood groups.

Bleeding time was estimated by Duke method and clotting time was estimated by capillary tube 
method.[7] To estimate the bleeding time by Duke method, a standard size skin puncture was made in the tip of one of the three (ring, middle or index) fingers by a sterile lancet under aseptic precautions and the bleeding was soaked every 30 seconds using a blotting paper until the bleeding stopped. Bleeding time was determined as time (seconds) from the infliction of finger prick injury to the absence of blood to the blotting paper. Normal range for bleeding time by this method was taken as 1-5 minutes. Similarly, clotting time was estimated by capillary tube method. Taking the aseptic measures, a standard depth skin puncture was made made in the tip of the three (ring, middle or index) fingers using a sterile lancet. The first drop of blood was discarded and the subsequent blood was filled into a capillary tube by capillary action. The capillary tube was held between palms, to keep the blood in body temperature. After a time lapse of 2 minute, the capillary tube was broken at about 1 to $2 \mathrm{~cm}$ from one end every 30 seconds until the appearance of a thin string of fibrin thread formed between the broken ends. The time lapse between the onset of bleeding until the formation of fibrin thread was noted to be the clotting time (seconds). Normal range for clotting time by capillary tube method was taken as 2-8 minutes. A stop watch was used to keep track of the timings in estimation of bleeding as well as clotting time.

Data was collected in Microsoft Excel worksheet and statistical analysis was done using SPSS version
16. Differences of BT and CT between the groups were compared by ANOVA test and the level of significance was set at a $p$ value of 0.05 .

\section{RESULTS}

Of the 376 students initially involved in the study, complete data was obtained in a total of 351 students, 160 males and 191 females, with the age ranging from 19-23 years. Only 32 students (9.1\%) belonged to the blood group $\mathrm{AB}$ while the student distribution in other blood groups were comparable (28.2-32.2\%). Regarding Rhesus groups, 11 students (3.1\%) were Rh negative (Table 1 ).

Table 1: Frequency distribution of students by sex, ABO type, and $\mathrm{Rh}$ type $(\mathrm{N}=351)$

\begin{tabular}{|l|l|c|c|}
\hline Groups & Subgroups & Frequency & Percentage \\
\hline \multirow{2}{*}{ Sex } & Male & 160 & 45.6 \\
\cline { 2 - 4 } & Female & 191 & 54.4 \\
\hline \multirow{3}{*}{$\begin{array}{l}\text { ABO } \\
\text { type }\end{array}$} & $\mathrm{A}$ & 99 & 28.2 \\
\cline { 2 - 4 } & $\mathrm{B}$ & 113 & 32.2 \\
\cline { 2 - 4 } & $\mathrm{AB}$ & 32 & 9.1 \\
\cline { 2 - 4 } & $\mathrm{O}$ & 107 & 30.5 \\
\hline \multirow{2}{*}{$\begin{array}{l}\text { Rhesus } \\
\text { type }\end{array}$} & Positive & 340 & 96.9 \\
\cline { 2 - 4 } & Negative & 11 & 3.1 \\
\hline
\end{tabular}

Table 2: Comparison of BT and CT in different blood and gender groups

\begin{tabular}{|c|c|c|c|c|}
\hline Group & Subgroups & $\begin{array}{l}\text { Number of } \\
\text { students }\end{array}$ & $\begin{array}{c}\text { BT, secs } \\
(\text { mean } \pm S D)\end{array}$ & $\begin{array}{c}\text { CT, secs } \\
(\text { mean } \pm \text { SD })\end{array}$ \\
\hline \multirow{5}{*}{ ABO type } & $\mathrm{A}$ & 99 & $141.52 \pm 105.07$ & $258.78 \pm 152.71$ \\
\hline & B & 113 & $122.66 \pm 68.8$ & $247.97 \pm 124.67$ \\
\hline & $\mathrm{AB}$ & 32 & $144.38 \pm 62.11$ & $226.88 \pm 84.14$ \\
\hline & $\mathrm{O}$ & 107 & $152.8 \pm 130.87$ & $282.34 \pm 185.43$ \\
\hline & \multicolumn{2}{|c|}{ ANOVA F (P value) } & $1.700(0.167)$ & $1.538(0.204)$ \\
\hline \multirow{3}{*}{ Rhesus type } & Positive & 340 & $138.71 \pm 101.67$ & $258.09 \pm 148.03$ \\
\hline & Negative & 11 & $152.73 \pm 96.24$ & $305.46 \pm 233.08$ \\
\hline & \multicolumn{2}{|c|}{ ANOVA F (P value) } & $0.203(0.652)$ & $1.047(0.307)$ \\
\hline \multirow{3}{*}{ Sex } & Male & 160 & $117.75 \pm 56.96$ & $209.06 \pm 83.06$ \\
\hline & Female & 191 & $157.07 \pm 124.58$ & $301.89 \pm 179.88$ \\
\hline & \multicolumn{2}{|c|}{ ANOVA F (P value) } & $13.558(<0.001)$ & $36.135(<0.001)$ \\
\hline
\end{tabular}


The mean bleeding and clotting times, for the total number of students, were $139.15( \pm 101.41)$ and $259.57( \pm 151.14)$ seconds respectively.

The mean $\mathrm{BT}$ and $\mathrm{CT}$ of each $\mathrm{ABO}$ blood group types were compared (Table 2). Both BT and CT were the highest in the blood group $\mathrm{O}$ whereas BT was shortest in group B and CT was shortest in group $\mathrm{AB}$. The differences in $\mathrm{BT}$ as well as $\mathrm{CT}$ among the $\mathrm{ABO}$ blood groups were statistically not significant $(\mathrm{p}>0.05)$. Similarly, values of both the parameters were found to be increased in $\mathrm{Rh}$ negative subjects than $\mathrm{Rh}$ positive, but the differences were also statistically insignificant. The relevancy of this finding is questionable as there were very few number of $\mathrm{Rh}$ negative subjects. However, the gender-wise comparison showed statistically significant differences. Both bleeding and clotting times were significantly longer among the females in comparison to the males $(\mathrm{p}<0.001)$.

A correlation between the two hemostatic parameters was explored. The Pearson's correlation showed a very highly significant correlation between $\mathrm{BT}$ and $\mathrm{CT}$ (correlation coefficient = $0.495, \mathrm{P}<0.001)$.

\section{DISCUSSION}

Blood grouping, bleeding time and clotting time are very important investigations performed before any surgical procedure, especially in conditions like frequent epistaxis, thrombosis, purpura etc. Blood grouping is the "must to do" hematological investigation before blood transfusion and is also a valuable information for solving medicolegal cases. Studies have also suggested possible differences of hemostatic function among the different blood groups. In this study, we aimed to verify the claims of $\mathrm{BT}$ and $\mathrm{CT}$ differences in the different $\mathrm{ABO}$ blood types in a sample population of 351 young adults (medical students). Bleeding time was estimated by Duke's method and clotting time by capillary tube method. Similar methods were also followed in many other studies excavating the relation of bleeding time and clotting time with different blood groups.[4, 10-15]. Blood group B was the commonest blood group followed by blood group $\mathrm{O}, \mathrm{A}$ and $\mathrm{AB}$ respectively in our study. It was found that bleeding time was highest in $\mathrm{O}$ blood group followed by AB, A and B blood groups (Table 2). Clotting time was also the highest in the same blood group followed by A, B and AB blood groups. However, the differences were not statistically significant $(\mathrm{p}>0.05)$.

Similar results have been depicted in study done by Baishya et al where they found prolonged $\mathrm{BT}$ in $\mathrm{O}$ blood group followed by $\mathrm{A}, \mathrm{B}$, and $\mathrm{AB}$. In contrast to our study, their results were statistically significant with $\mathrm{P}<0.05$. In their study, blood group O was more common followed by B, A, and AB.[13] Kaur et al also observed similar results where they found bleeding time was prolonged in blood group $\mathrm{O}$ followed by $\mathrm{B}, \mathrm{AB}$, and $\mathrm{A}$ whereas clotting time was highest in blood group $\mathrm{B}$ followed by $\mathrm{O}, \mathrm{AB}$, and $\mathrm{A}$; although the difference was statistically insignificant.[4] Similar to our study, Blood group $\mathrm{B}$ was the commonest, followed by blood groups $\mathrm{O}$, $A$, and $A B$ in their study. In contrast to our findings, there was prolonged bleeding time in the $\mathrm{AB}$ blood group individuals $(\mathrm{P}<0.001)$ and prolonged clotting time in the $\mathrm{B}$ blood group individuals $(\mathrm{P}=0.002)$ compared to other groups in a study performed by Sasekala M et al.[12] The study showed statistically significant difference of $\mathrm{BT}$ and $\mathrm{CT}$ among $\mathrm{ABO}$ blood groups. The most prevalent blood group was $\mathrm{O}$ followed by $\mathrm{A}, \mathrm{B}$ and $\mathrm{AB}$. Bleeding time was found to be prolonged in both $\mathrm{O}$ and $\mathrm{B}$ blood groups and less in $A$ and $A B$ groups, but with no statistical significance $(P=0.85)$. Similarly, clotting time was found to be longer in blood groups $\mathrm{O}$ and $\mathrm{B}$ but the differences were not statistically significant. Regaring gender-wise difference, a study done by Benjamin et al found that $\mathrm{BT}$ was higher in males $(\mathrm{P}<0.05)$ while $\mathrm{CT}$ was higher in females $(\mathrm{P}>0.05)$. [15]

Thus, most of the results including our study direct towards the greater risk of bleeding in individuals with blood group $\mathrm{O}$ as the results have depicted longer BT and CT in O blood group, with non-O blood groups in the higher side of risk for thrombosis. Studies has supported to a concept that compared to the type O blood group, the non-O blood group individuals can have an increased risk of thrombosis due to the higher levels of vWF. $[16,17]$ It is also stated that the $A B O$ group can affect the vWF catabolism, which means that the plasma vWF levels may depend on blood group of the individual. vWF is $25 \%$ more in non-O blood group individuals compared to blood group $\mathrm{O}$ individuals.[16]

A statistically significant higher values of bleeding time and clotting time were found in females in comparison to males $(\mathrm{P}<0.001)$. Similar results have been depicted in many other studies. $[4,13,14]$ 
Females have higher levels of estrogen. Estrogen administration caused a slightly increase in fibrinogen clotting time values (or decrease plasma fibrinogen values) in the rabbits.[18] This may highlight upon the physiological basis of increased $\mathrm{BT}$ and $\mathrm{CT}$ in females.

The BT and CT differences in the Rh positive and negative groups may not be suitable for generalization due to the groups being disproportionate in size. The study was conducted in a single center with participants within narrow range of age and of the medical studentoccupation. Thus, all participants essentially have mostly similar characteristics. Larger sample studies, inclusive of wider age ranges and occcupational variations, and also evaluating other parameters of hemostatic function such as plasma vWF levels should be conducted to verify the results.

\section{CONCLUSION}

Our study result showed increased bleeding time and clotting time in blood group $\mathrm{O}$ in comparison to the other blood groups of $\mathrm{ABO}$ blood group system, although differences were statistically not significant. The study hinted a greater risk of bleeding in $\mathrm{O}$ blood groups compared to non-O groups. Hence, the findings may be helpful to identify the risk group and take prior preventive measures.

\section{CONFLICT OF INTEREST}

None

\section{REFERENCES}

1. Maxwell MW, Richard G, Dane RB et al. Clinical Hematology. 9th ed. Pennsylvania: Lea and Febiger 1993; 617-30.

2. Dzieczkowski JS, Tiberghien P, Anderson KC. Transfusion biology and therapy. In Fauci AS, Braunwald E, Kasper DL et al Eds. Harrison's Principles of Internal Medicine. 17th ed. USA: Mc Graw Hill 2008; 708.

3. Roy B, Banerjee I, Sathian B, Mondal M, Saha CG. Blood group distribution and its relationship with bleeding time and clotting time: a medical school based observational study among Nepali, Indian and Sri Lankan students. Nepal J Epidemiol. 2011; 1:135-40.

4. Kaur M, Singh A, Bassi R, Kaur D. Blood group distribution and its relationship with bleeding and clotting time. Natl J Pharm Pharmacol Physiol. 2015; 5: 253-7.

5. Ruggeri ZM. Structure of von Willebrand factor and its functioning platelet adhesion and thrombus formation. Best Prac Res Clin Haematol. 2001; 14: 2579.

6. Sadler JE. Von Willebrand factor. Ann Rev Biochem. 1998; 67: 39524.

7. Pal GK, Pal Parvati. Text book of practical physiology. 2nd ed. Universal press 2005; 107-9.

8. Chanu LL, Singh BR, Rajkumari B et al. Bleeding time in different blood groups- A cros sectional study. J. Evolution Med. Dent. Sci. 2019: 8; 1813-15.

9. Harrison P. Platelet function analysis. Blood Rev. 2005; 19: 111-23.

10. Ivy AC, Shapiro PF, Melnick P. The bleeding tendency in jaundice. Surg Gynecol Obstet. 1953; 60: 781-4.

11. Sutor AH. The bleeding time in pediatrics. Semin Thromb Hemost. 1998; 24: 531-43.

12. Sasekala M, Saikumar P. Relationship between bleeding time and clotting time among gender difference and varying blood groups in UG medical students. Journal of Dental and Medical Sciences. 2013; 10: 40-43.

13. Baishya $R$, Sarkar R, Barman B. Blood group and its relationship with bleeding time and clotting time- an observational study among the 1st MBBS students of Gauhati medical college, Guwahati. Int J Res Med Sci. 2017; 5: 4147-50.

14. Waghmare RV, Muniyappanavar NS. Influence of Blood Groups on Bleeding and Clotting Time. Internatl Phsiol. 2018; 6: 200-204.

15. Benjamin JJ, Geetha MB. Study of association of bleeding and clotting time with blood group among young adults. Indian J Clin Anat Physiol. 2020;7: 350-353

16. Franchini M, Capra F, Targher G, Montagnana M, Lippi G. Relationship between $A B O$ blood group and von Willebrand factor levels: from biology to clinical implications. Thromb J. 2007; 5: 14.

17. Jenkins PV, O'Donnell JS. ABO blood group determines plasma von Willebrand factor levels: a biologic function after all? Transfusion. 2006; 46:1836-44.

18. Ercan M, YeðÝn E, AkdenÝz H, Irmak H, Bayiroðlu F and Tuncer $Y$. Effect of estrogen on fibrinogen clotting time in rabbits. Turk J Vet Anim Sci. 1998; 22: 13740. 